\title{
SSS
}

ABSTRACT Scientific and engineering research increasingly involves multidisciplinary collaboration, sometimes across multiple organizations. Technological advances have made such cross-boundary projects possible, yet they can carry high coordination costs. This study investigated scientific collaboration across disciplinary and university boundaries to understand the need for coordination in these collaborations and how different levels of coordination predicted success. We conducted a study of 62 scientific collaborations supported by a program of the US National Science Foundation in 1998 and 1999. Projects with principal investigators (PIs) in more disciplines reported as many positive outcomes as did projects involving fewer disciplines. By contrast, multi-university, rather than multidisciplinary, projects were problematic. Projects with PIs from more universities were significantly less well coordinated and reported fewer positive outcomes than projects with Pls from fewer universities. Coordination mechanisms that brought distant researchers together physically slightly reduced the negative impact of collaborations involving multiple universities. We discuss implications for theory, practice, and policy.

Keywords distributed work, geographic dispersion, innovation, multidisciplinary, organizational boundaries, project size, project work, scientific collaboration, universities

\section{Collaborative Research Across Disciplinary and Organizational Boundaries}

\author{
Jonathon N. Cummings and Sara Kiesler
}

Scientists have collaborated with one another for centuries (Finholt \& Olson, 1997). Recently, policymakers have begun to encourage and support two or more disciplines working together in applied and basic science - multidisciplinary collaboration (Grinter et al., 1999; Teasley \& Wolinsky, 2001; Chin et al., 2002). Important fields such as oceanography and cognitive science have developed out of multidisciplinary collaborations (Hesse et al., 1993; Schunn et al., 2002). Because the formal organization of science and engineering in universities and industrial laboratories usually follows disciplinary boundaries, multidisciplinary collaboration often requires crossing organizational boundaries as well. The geologist who collaborates with a computer scientist often works in another department or university as well as in a different field.

In the past, dispersed forms of collaboration would have been made difficult by physical distance between scientists, which not only reduced the likelihood of collaboration, but also had a negative impact on success 
(Allen, 1977; Kraut et al., 1990; Kiesler \& Cummings, 2002). Today, dispersed collaborations are more feasible because communication technologies allow scientists to exchange news, data, reports, equipment, instruments, and other resources (Hesse et al., 1993; Kouzes et al., 1996; Finholt, 2002). Fields such as particle physics and mathematics have relied on computer-mediated communication for several decades (Walsh \& Bayma, 1996). A recent explosion in dispersed collaboration has been spawned by funding agencies, such as the National Science Foundation (NSF) in the USA and the Framework Programmes in the European Union, which aim for diverse organizational representation.

Recent research suggests that, even with some signs of progress (Sonnenwald, 2003), technology has not yet conquered distance (Mark et al., 1999; Herbsleb et al., 2000; Cramton, 2001; Hinds \& Bailey, 2003). A major challenge for dispersed scientific collaborations is coordinating work so that scientists can effectively use one another's ideas and expertise without frequent face-to-face interaction. Coordination is the integration or linking together of different pieces of a project to accomplish a collective task (van de Ven et al., 1976). Although some coordination can be accomplished through project structure, for example, by creating clear lines of authority and division of labor, science is dynamic, and members of the collaboration still must talk out common problems, discuss shared resources, and monitor and review the work to make joint progress (Malone \& Crowston, 1994; Kraut \& Streeter, 1995).

Multidisciplinary collaborations also must manage interpersonal relationships within the project. Scientists from different disciplines have usually trained in different departments, have had different advisors, publish in different journals, and attend different conferences. Their social bonds are likely to be comparatively weak (Granovetter, 1973), increasing the difficulty of developing trust and effective interdependence.

\section{Innovation in Multidisciplinary Collaborations}

An important claim favoring multidisciplinary collaborations is that they promote innovation. We define innovation as the successful implementation of creative ideas, tasks, or procedures (Amabile, 1988). In science and engineering, innovations are technical discoveries or insights, new ways to use existing technologies, or radical approaches to problems (Henderson \& Clark, 1990; Utterback, 1994; Hargadon, 1998; O’Connor \& Rice, 2001). Multidisciplinary projects should increase the likelihood of innovation due to their juxtaposition of ideas, tools, and people from different domains. As the Internet and other forms of computing have enhanced the potential for this 'distributed intelligence', policymakers in science and engineering expect greater innovation from such projects (Zare, 1997).

There is tension between the benefits to innovation of working across disciplinary and organizational boundaries versus the risks that arise from the costs of coordination and relationship development in these collaborations. Dispersed science and engineering projects are forms of innovation 
systems that are meant to create, diffuse, and use diverse sources of knowledge (Carlsson et al., 2002). How researchers manage such projects and organize work to be productive has been the subject of much discussion over the years (Hagstrom, 1964). Some authors distinguish between the amount of bureaucracy versus participation in the scientific collaboration (Chompalov et al., 2002), whereas others focus on the extent to which work is project-based (Hobday, 2000). The existing literature provides no clear guidelines to managing coordination and relationship development in multidisciplinary collaborations.

Multidisciplinary projects may require new approaches to coordination to get the work done and to foster trust. When working with other disciplines requires working across organizational boundaries. For example, as when a biologist at one university collaborates with a computer scientist at another university, the need for coordination increases due to field differences and to geographic dispersion. The research question we pose in this paper is how collaborations involving multidisciplinary and multi-organizational relationships achieve successful coordination.

\section{Methods}

The authors studied a research program created by the Computer and Information Science and Engineering Directorate (CISE) of the US NSF. The program was called 'Knowledge and Distributed Intelligence' (KDI). Its purpose was 'to span the scientific and engineering communities ... to generate, model, and represent more complex and cross-disciplinary scientific data from new sources and at enormously varying scales'. The program was highly competitive. It supported only 40 awards out of 697 proposals in 1998, and 31 awards out of 554 pre-proposals and 163 full proposals in 1999. These projects were supported at US $\$ 1.5$ million each over 3 years. We report analyses of 62 of the 71 projects awarded this funding.

In the fall of 2001, NSF asked the authors to organize a workshop of research grantees to assess what had happened in the KDI research projects. NSF invited the principal investigator (PI) and one co-PI from each of the $71 \mathrm{KDI}$ projects to the workshop. Researchers from 52 research projects attended the workshop, held in late April 2002. At this workshop we asked researchers, organized into small randomly assigned groups, to discuss with one another how their research projects were organized and managed, the kinds of outcomes they generated, and the ways in which their research experience could inform future program evaluation. During three mornings of group discussion, note-takers as well as participants compiled lists of experiences, outcomes, and suggestions. We asked the participants to send us copies of reports they had written and links to their websites.

During the workshop and when reviewing our notes later, we observed that almost all of the projects faced serious obstacles to collaboration. 
These obstacles ranged from different teaching schedules to different visions of project objectives. For example, one PI, whose university ran on the semester system, ran into difficulty finding times to meet with his coPIs, whose university ran on the quarter system. Another PI spoke of how he had to negotiate budgets, contract language, intellectual property, indirect costs, and human subjects procedures across universities. Still another discussed how students at different universities had been trained with different statistical software, an obstacle to sharing analyses until everyone could agree on a common approach. Many PIs discussed distance as a barrier to meeting, and recounted how their early enthusiasm for travel to one another's sites was dampened over the course of the project. To overcome these obstacles, project PIs or co-PIs employed traditional approaches to coordination, such as weekly laboratory meetings, as well as mechanisms they invented to maintain communication and keep the project on track. For instance, a few PIs arranged for graduate student exchanges to promote cross-training of students in the project.

We observed considerable variation in the number and types of outcomes of these projects. Some of the projects produced mainly computerbased tools or resources, such as shared data repositories that could be used in other scientific projects. In other projects, PIs' publications, presentations, and workshops opened up an entirely new field of endeavor. Others were effective in training graduate students who later went on to fill top research jobs, or they gave undergraduates the experience they needed to earn places in graduate programs. Others worked with community groups, for example, by creating museum exhibits, elementary school classroom materials, or websites designed for public use.

\section{Post-Workshop Survey}

From the workshop notes and documentation from PIs' websites and reports, we created an online survey to systematically assess the coordination mechanisms and project outcomes that workshop participants had described in connection with their own projects. We created items that represented the most frequent coordination mechanisms and project outcomes mentioned in the workshop. In Fall 2002, we surveyed all KDI PIs and co-PIs and a random sample of students and staff in each project. We asked this entire sample whether or not their project had used each mechanism or had produced that outcome. Our questionnaire included the following items designed to measure coordination: direct supervision of work; use of special events, such as workshops, to get people together in the same place; travel in order to work together or meet; and regular use of face-to-face meetings, email, and telephone. If respondents checked an item, they were asked to describe how they used the respective mechanism in their project. They also could add items that were not otherwise listed, though no single item was mentioned often enough to warrant inclusion in our analysis. The items measuring project outcomes were grouped into 
categories corresponding to the NSF's goals: generation of new ideas and knowledge (for example, publications, patents, grants), generation of tools and infrastructure for research (for example, software applications, databases), training of scientists and engineers (for example, $\mathrm{PhD}$ students, undergraduates), and outreach and public understanding and use of science and engineering (for example, school and community projects, links with industry). Respondents checked whether their project had achieved outcomes within each of these categories; if so, they were asked to describe these outcomes.

\section{Results}

We report results for $62(87 \%)$ of the 71 research projects in which at least one PI or co-PI answered the survey and provided documentation of project outcomes. PIs or co-PIs usually said they spoke for the entire project, inflating scores for those projects where more than one PI responded to the survey. Therefore, we report data for the most senior respondent on each project, either the PI $(n=37)$ or, when the PI did not respond, the co-PI $(n=25)$. Preliminary analyses show that the reports by PIs and co-PIs were equivalent. For example, PIs and co-PIs were equally likely to report positive outcomes, regardless of their projects' size, or of the number of disciplines or universities involved in their projects. We used data available from the web, NSF reports, and other NSF data to verify factual information such as project size, disciplines, and universities.

Each project in the sample of 62 projects had one PI and up to five coPIs; the average number of co-PIs was three. The PIs and co-PIs represented 40 disciplines, including computer science $(16 \%)$, electrical engineering $(13 \%)$, other engineering disciplines $(12 \%)$, psychology $(12 \%)$, physics $(9 \%)$, mathematics $(9 \%)$, and biology ( $8 \%)$. These PIs and co-PIs were employed by nearly 100 organizations. All but five of these organizations were universities. Henceforth in this paper, we refer to the PI organizations as 'universities', in that these were $95 \%$ of the sample. Of the research projects, 26 were at a single university and 36 , a majority, were collaborations of multiple universities, up to six (see Figure 1). A greater number of universities was particularly characteristic of those projects involving more disciplines (correlation $r=.29$; see Figure 2). This finding supports our argument that multidisciplinary projects are likely to require coordination across organizations and over distance.

The mechanisms used for coordination across projects varied in popularity. At least $20 \%$ of the projects used the coordination mechanisms reported in Table 1. A few projects used communication technologies other than regular telephone and email at least once a month, such as conference calls $(13 \%)$, video conferencing $(8 \%)$, instant messaging (3\%), and online forum discussions $(8 \%)$. However, these were too few to include in the subsequent analyses.

Respondents reported many different project outcomes and products, 
ranging from an algorithm for large-scale predictive species distribution to a blood-flow simulation for prosthetic heart valves, a system to support manual manipulation of virtual objects, an undergraduate thesis published in a top journal, and a partnership with a major corporation. We ran a confirmatory factor analysis, which showed that the items were clustered into four independent categories of outcomes that mapped onto the four NSF goals we had previously specified: ideas and knowledge (Ideas), tools and infrastructure (Tools), student training (Training), and outreach (Outreach) (Table 2). For subsequent analyses, we used items from the four factors that loaded together at least at the .4 level on each factor. Every

FIGURE 1

Distribution of principal investigator (PI) disciplines (A) and PI universities (B) $(N=64)$.

(A)

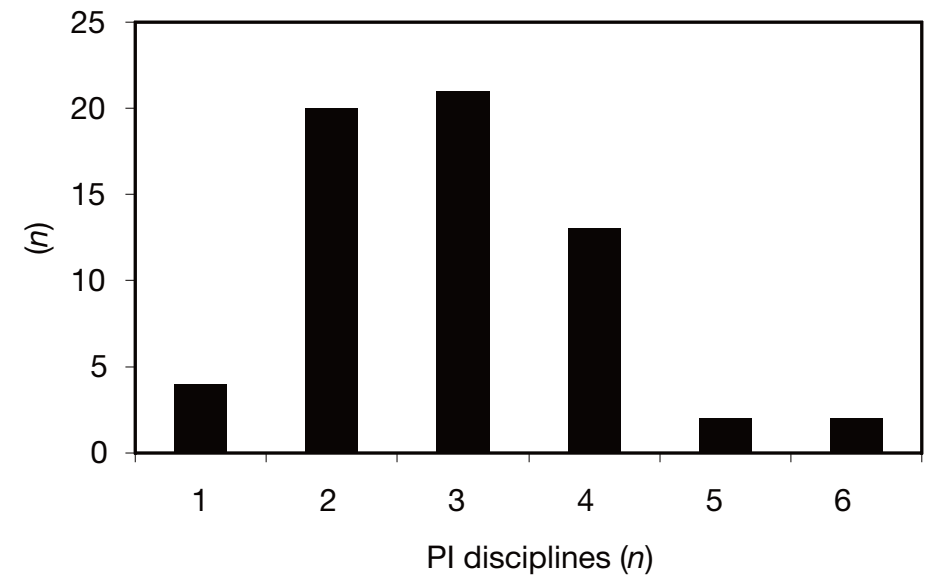

(B)

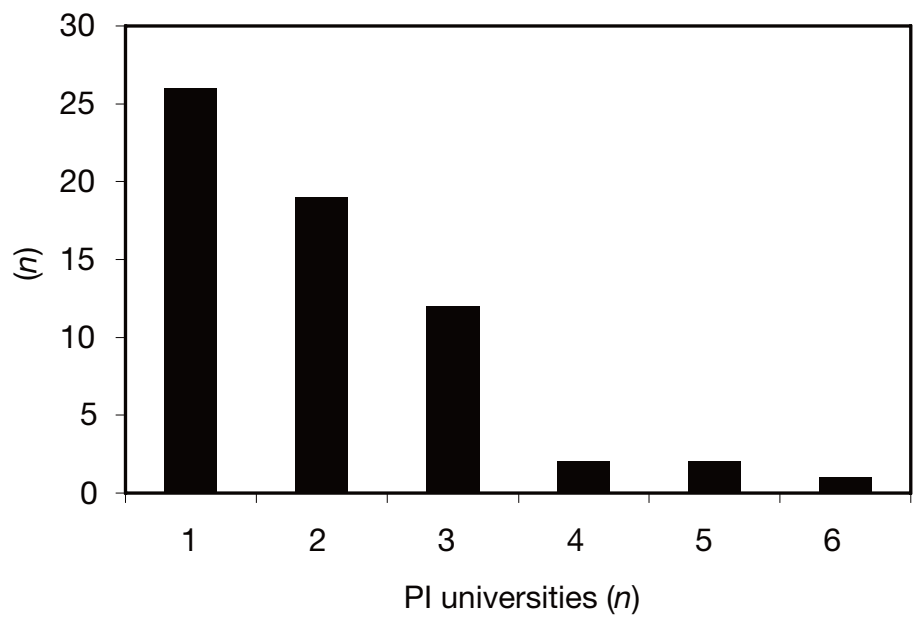


FIGURE 2

Scatter plot showing the relationship between the number of principal investigator (PI) disciplines in a project and the number of PI universities in a project $(r=.29)$.

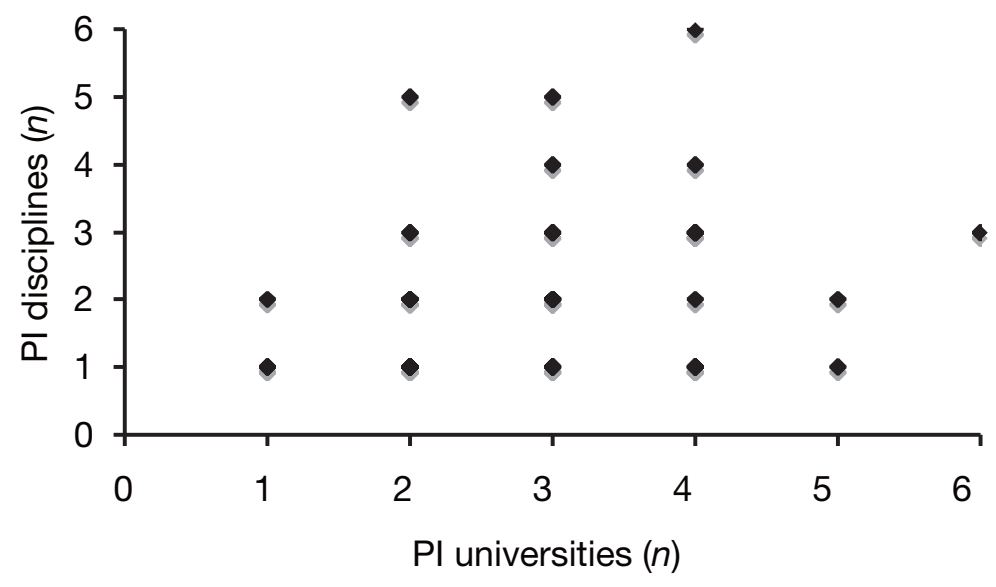

project received a score for each of four categories, Ideas (Cronbach's alpha $=.55$ ), Tools (Cronbach's alpha $=.51$ ), Training (Cronbach's alpha $=.54$ ), and Outreach (Cronbach's alpha $=.28$ ), depending on the number of items to which the PI or co-PI responded 'yes'. For instance, in the Ideas category, a project could receive up to 4 points if the PI or co-PI reported that his or her project started a new field or area of research, came up with new grants or spin-off projects, developed new methodologies, and was recognized with an award for contributions to the field. Projects' average score in this category was 2 points. Respondents who answered 'yes' to any item had to document their answer by describing the specific outcome, giving a citation, naming the student, and so forth. We intended this requirement to discourage gratuitous entries.

\section{TABLE 1}

Coordination mechanisms used by projects $(N=62$ projects $)$

Coordination mechanism items (0 no: 1 yes)

At least monthly face-to-face project meetings $\quad 55$

At least monthly phone or email on project $\quad 84$

Held conference or workshop $\quad 55$

Worked on project during conference or workshop $\quad 52$

$\begin{array}{ll}\text { Sabbatical to work with collaborators } & 21\end{array}$

Traveled by airplane to work with collaborators $\quad 52$ 
TABLE 2

Project outcomes $(N=62$ projects $)$

\begin{tabular}{ll}
\hline & $\begin{array}{l}\text { Projects saying } \\
\text { 'yes' (\%) }\end{array}$ \\
\hline Project outcome items (yes/no) & 58 \\
\hline Sdeas & 58 \\
$\quad$ Crarted new field or area of research & 66 \\
Developed new methodologies & 19 \\
Recognized with award for contribution to field & \\
Tools & 71 \\
Created new software & 13 \\
Created new hardware & 47 \\
Generated new datasets & 15 \\
Submitted patent application & 76 \\
Training & 48 \\
Undergraduate/graduate student finished thesis or dissertation & 42 \\
Undergraduate/graduate/post-doc got academic job & \\
Undergraduate/graduate/post-doc got industry job & 27 \\
Outreach & 27 \\
Formed partnership with industry & 65 \\
Formed community relationships through research & \\
Formed collaborations with different researchers &
\end{tabular}

Note: The items above loaded above .4 on four separate factors, as categorized above. Each project could have 0 to 4 points in the Ideas and Tools categories, and 0 to 3 points in the Training and Outreach categories.

\section{Effects of Multiple Disciplines and Multiple Universities on Project Coordination}

We argued that more disciplines and/or universities involved in a research project might impair project coordination. We performed statistical tests, using ordinary least squares regression, to examine the simultaneous effects of the main predictor variables, number of PI disciplines and number of PI universities, on their projects' use of each of the coordination mechanisms. The regression analyses statistically control for year the project started, size of the project in budget and people, and level of research and development in the main PI's university. Table 3 shows these analyses. The findings were that, to a statistically significant degree, more PI universities involved in a project predicted fewer coordination mechanisms used in that project. More PI universities on a project predicted a lower level of faculty, post-doctoral, and graduate student direct supervision, a reduced likelihood of having created a project-related course, seminar, or invited speakers, and a much lower likelihood of having at least monthly project meetings. The results also show that, with more universities involved, the pattern of coordination mechanisms changed. PIs were more likely to hold a conference or workshop and to work on the project at a conference or a workshop. (Holding a conference or workshop, however, was less likely when the PIs were from different disciplines.) The 
analyses taken as a whole suggest that distance and organizational boundaries interfered with those coordination mechanisms that involve frequent, spontaneous conversation and problem-solving (direct supervision, faceto-face meetings, seminars, courses). Distance and organizational boundaries impelled researchers to use other means of getting together, such as putting together a workshop to which all the collaborators could travel. Our data do not show that PIs from multiple universities used technology or traveled more than PIs who were collocated.

\section{Effects of Multiple Disciplines and Multiple Universities on Project Outcomes}

Table 4 (Model 1) shows the results from regression analyses of the impact of number of PI disciplines and number of PI universities on project outcomes. The number of disciplines and control variables had little impact, except that more disciplines in the project tended to be less beneficial for student training. The strongest statistical effects derived from the number of universities. Having more PI universities on a project was significantly negatively associated with the generation of new ideas and knowledge, and it was also negatively associated with student training and project outreach, though this association did not reach statistical significance.

\section{Mediation Analysis}

We conducted an analysis to examine how coordination mechanisms were related to outcomes. We found that, controlling for the number of universities, coordination mechanisms predicted the outcomes of projects. The most effective coordination mechanism overall was direct supervision, especially by faculty and graduate students; this mechanism was used more by single university projects. Face-to-face mechanisms, such as holding a seminar, inviting outside speakers, and having face-to-face laboratory meetings, were especially important in student training. The mechanisms used in multiple university projects, such as holding a workshop or conference, and travel, were somewhat effective in helping the project generate new ideas.

To test whether coordination mechanisms partly caused the negative relationship between number of universities and project outcomes, we conducted a mediation analysis (Baron \& Kenny, 1986). We compared a model using only the number of PI universities and disciplines (plus controls) to predict project outcomes (Model 1 in Table 4), with a model adding in all the coordination variables (Model 2). If negative beta coefficients for the number of PI universities are smaller or reversed in Model 2 compared with Model 1, that difference suggests that coordination mechanisms could account for the lower degree of success of projects with more PI universities. The beta coefficients for number of PI universities in Model 2 versus Model 1 is indeed smaller in predicting Ideas outcomes (-.33 vs -40 ), Training outcomes (.27 vs -.22 ), and Outreach outcomes (-.17 vs -.26 ), showing some support for the idea that a lack of coordination was 
TABLE 3

Regression analyses predicting the amount of project coordination from the number of principal investigator (PI) disciplines and number of PI universities in the project $(\mathrm{N}=62$ projects)

\begin{tabular}{|c|c|c|c|c|c|c|c|c|c|c|}
\hline & \multicolumn{10}{|c|}{ Coordination mechanisms used in projects } \\
\hline & $\begin{array}{l}\text { Faculty } \\
\text { supervised } \\
\text { tasks }\end{array}$ & $\begin{array}{l}\text { Post-doc } \\
\text { supervised } \\
\text { tasks }\end{array}$ & $\begin{array}{l}\text { Graduate } \\
\text { student } \\
\text { supervised } \\
\text { tasks }\end{array}$ & $\begin{array}{l}\text { Held seminar } \\
\text { or invited } \\
\text { speakers }\end{array}$ & $\begin{array}{l}\text { At least } \\
\text { monthly } \\
\text { face-to-face } \\
\text { project } \\
\text { meetings }\end{array}$ & $\begin{array}{l}\text { At least } \\
\text { monthly } \\
\text { phone or } \\
\text { email on } \\
\text { project }\end{array}$ & $\begin{array}{l}\text { Held } \\
\text { conference } \\
\text { or } \\
\text { workshop }\end{array}$ & $\begin{array}{l}\text { Worked on } \\
\text { project } \\
\text { during } \\
\text { conference } \\
\text { or } \\
\text { workshop }\end{array}$ & $\begin{array}{l}\text { Sabbatical to } \\
\text { work with } \\
\text { collaborators }\end{array}$ & $\begin{array}{l}\text { Traveled by } \\
\text { airplane to } \\
\text { work with } \\
\text { collaborators }\end{array}$ \\
\hline \multicolumn{11}{|l|}{ Predictor variables } \\
\hline $\begin{array}{l}\text { Number of PI } \\
\text { disciplines }\end{array}$ & -.18 & .17 & -.01 & -.07 & -.07 & -.03 & $-.43^{\dagger}$ & -.29 & $.67^{\dagger}$ & .08 \\
\hline $\begin{array}{l}\text { Number of PI } \\
\text { universities }\end{array}$ & $-.22^{\dagger}$ & $-.39^{\dagger}$ & $-.56^{\star}$ & $-.62^{\star \star}$ & $-.64^{\star \star}$ & .07 & $.37^{\star}$ & $.38^{\dagger}$ & -.06 & .23 \\
\hline \multicolumn{11}{|l|}{ Controls } \\
\hline Year started & $1.25^{\star \star}$ & $1.31^{\star \star}$ & .44 & $1.09^{\star \star}$ & $1.41^{\star \star}$ & $.66^{\star \star}$ & $.91^{\star}$ & $.77^{\dagger}$ & $.86^{\dagger}$ & .43 \\
\hline Budget & -.16 & -.26 & .04 & -.04 & -.13 & .09 & .08 & -.14 & -.11 & -.23 \\
\hline $\begin{array}{l}\text { University research and } \\
\text { development }\end{array}$ & -.05 & -.14 & .05 & -.08 & -.04 & .12 & .00 & .05 & .00 & .10 \\
\hline Number of PIs & .19 & -.18 & .49 & .36 & .17 & .05 & -.18 & -.04 & $-.85^{\star}$ & .02 \\
\hline Number of post-docs & .09 & $.39^{\star \star}$ & .20 & $.25^{\star}$ & .11 & .00 & $.27^{\star}$ & .14 & -.09 & .03 \\
\hline $\begin{array}{l}\text { Number of graduate } \\
\text { students }\end{array}$ & -.02 & -.18 & .00 & -.1 & -.17 & -.01 & -.18 & -.07 & -.04 & .21 \\
\hline$R^{2}$ & .86 & .56 & .44 & .71 & .66 & .85 & .65 & .56 & .31 & .57 \\
\hline
\end{tabular}

Note: Values in table are beta coefficients. Statistical significance is indicated by : ${ }^{\dagger} p<.10 ;{ }^{\star} p<.05 ;{ }^{\star \star} p<.01$. Positive beta values indicate that a higher value of the predictor (or control) variable predicts a higher likelihood that the coordination mechanism was used in a project. Negative beta values indicate that a higher value of the predictor (or control) variable predicts a lower likelihood that the coordination mechanism was used in a project. For instance, the significant negative beta $\left(-.64^{\star \star}\right)$ for number of universities predicting monthly face-to-face project meetings means that when more PI universities were involved in a project, the project team was less likely to have held at least monthly face-to-face project meetings. 
TABLE 4

Regression analyses testing the effects of number of principal investigator (PI) disciplines, number of PI universities, and number of coordination mechanisms on project outcomes $(N=62$ projects $)$

\begin{tabular}{|c|c|c|c|c|c|c|c|c|}
\hline & \multicolumn{2}{|c|}{ Ideas } & \multicolumn{2}{|c|}{ Tools } & \multicolumn{2}{|c|}{ Training } & \multicolumn{2}{|c|}{ Outreach } \\
\hline & Model & Model & Model & Model & Model & Model & Model & Model \\
\hline & 1 & 2 & 1 & 2 & 1 & 2 & 1 & 2 \\
\hline \multicolumn{9}{|l|}{ Controls (not shown) } \\
\hline \multicolumn{9}{|l|}{ Predictor variables } \\
\hline $\begin{array}{l}\text { Number of PI } \\
\text { disciplines }\end{array}$ & -.08 & .09 & .25 & .16 & .00 & .01 & .25 & .25 \\
\hline $\begin{array}{l}\text { Number of PI } \\
\text { universities }\end{array}$ & $-.40^{\star \star}$ & $-.33^{\dagger}$ & .00 & $.39^{\dagger}$ & -.22 & .27 & -.26 & -.17 \\
\hline \multicolumn{9}{|l|}{$\begin{array}{l}\text { Coordination } \\
\text { mechanisms }\end{array}$} \\
\hline $\begin{array}{l}\text { Faculty supervised } \\
\text { tasks }\end{array}$ & & $.35^{\star}$ & & $.42^{\dagger}$ & & $.38^{\star}$ & & .26 \\
\hline $\begin{array}{l}\text { Post-doc supervised } \\
\text { tasks }\end{array}$ & & .01 & & .02 & & -.13 & & .00 \\
\hline $\begin{array}{l}\text { Graduate student } \\
\text { supervised tasks }\end{array}$ & & .13 & & $.24^{\star}$ & & $.17^{\star}$ & & .05 \\
\hline $\begin{array}{l}\text { Held seminar or } \\
\text { invited speaker }\end{array}$ & & -.07 & & .08 & & $.31^{\star}$ & & -.10 \\
\hline $\begin{array}{l}\text { At least monthly } \\
\text { face-to-face project } \\
\text { meetings }\end{array}$ & & .17 & & .12 & & $.24^{\star}$ & & .17 \\
\hline $\begin{array}{l}\text { At least monthly } \\
\text { phone or email on } \\
\text { project }\end{array}$ & & .03 & & -.19 & & -.23 & & .12 \\
\hline $\begin{array}{l}\text { Held conference or } \\
\text { workshop }\end{array}$ & & .13 & & -.05 & & -.11 & & -.03 \\
\hline $\begin{array}{l}\text { Worked on project } \\
\text { during conference or } \\
\text { workshop }\end{array}$ & & .11 & & -.07 & & .01 & & .06 \\
\hline $\begin{array}{l}\text { Sabbatical to work } \\
\text { with collaborators }\end{array}$ & & -.04 & & $.19^{\star}$ & & .08 & & .08 \\
\hline $\begin{array}{l}\text { Traveled by airplane } \\
\text { to work with } \\
\text { collaborators }\end{array}$ & & $.24^{\star}$ & & .16 & & $.17^{\dagger}$ & & .13 \\
\hline$R^{2}$ & .87 & .77 & .78 & .68 & .87 & .77 & .73 & .68 \\
\hline
\end{tabular}

Note: Values in table are beta coefficients. Statistical significance is indicated by : ${ }^{\dagger} p<.10$; ${ }^{\star} p<.05 ;{ }^{\star \star} p<.01$. Model 1 shows the effects of number of PI disciplines and number of PI universities on project outcomes. A positive beta indicates that the predictor is associated with more outcomes in each category shown. A negative beta indicates that the predictor is associated with fewer outcomes in each category shown. Model 2 shows the combined effects of number of PI disciplines, number of PI universities, and number of coordination mechanisms on outcomes. The comparison is a mediation analysis (Baron \& Kenny, 1986). If the beta for number of disciplines or universities is lower in Model 2 than in Model 1, one can infer that coordination mechanisms are partly mediating (causing) the effect of the predictor on outcomes. 
associated with poorer outcomes of these types. Note that the opposite occurred in predicting outcomes in the Tools category. That is, the beta coefficients for number of PI universities become significant and positive when coordination is added to the model. This finding suggests that, controlling for coordination effects (which are all positively associated with good outcomes, as in the other models), more PI universities contributed to better Tools outcomes. The finding suggests that research to produce computer-based tools might be qualitatively different from other kinds of research.

In sum, the results show that more PI universities rather than more PI disciplines were problematic for collaborations, and that using more coordination mechanisms could reduce the negative impact somewhat. Unfortunately, having PI universities involved in a project significantly reduced the likelihood that PIs would actually employ sufficient coordination mechanisms.

\section{Discussion}

Despite widespread excitement about dispersed collaboration reflected in terms like 'virtual team', 'eScience', and 'cyberinfrastructure', there appear to remain a number of challenges that scientists encounter when they work across organizational boundaries. The multi-university projects we studied were less successful, on average, than projects located at a single university. We show these trends in Figure 3. The overall trend in Figure 3 is a downward slope from single university to multiple universities. Also, Figure 3 indicates a marginally significant overall interaction effect, suggesting that multidisciplinary projects can be highly successful in producing new ideas and knowledge, and outreach, when they are carried out within one university. Projects with many disciplines involved excelled when they were carried out within one university. We also found that when projects used more coordination mechanisms, they were more successful, but projects involving more universities used fewer coordination mechanisms than did projects involving fewer universities. Using more coordination mechanisms partly made up for distance and organizational boundaries, but even controlling for the number of coordination mechanisms used, projects involving more universities were less successful.

Our findings are open to alternative explanations that need to be examined before drawing strong inferences. One problem is that the projects investigated here represent only $6 \%$ of all the proposals sent to the program. We do not know what forms of selection bias operated. For example, did peer reviewers give higher scores to multi-university projects because they liked the number of organizations and regions represented? If reviewers gave multi-university proposals extra points for including many organizations, and if doing so is independent of scientific merit, then the poorer outcomes of multi-university projects could be explained by a difference in intrinsic merit. To check on this possibility, it will be necessary to examine the peer review process. 


\section{FIGURE 3}

Project outcomes in single university and multi-university projects ( $N=62$ projects). (A), Ideas; (B), Tools; (C), Training; (D), Outreach. The unit of measurement on the $y$ axis is the number of items checked on the post-workshop survey for each outcome. Based on a median split, there were 30 projects with one to three principal investigator (PI) disciplines and 32 projects with four to six PI disciplines.

(A)

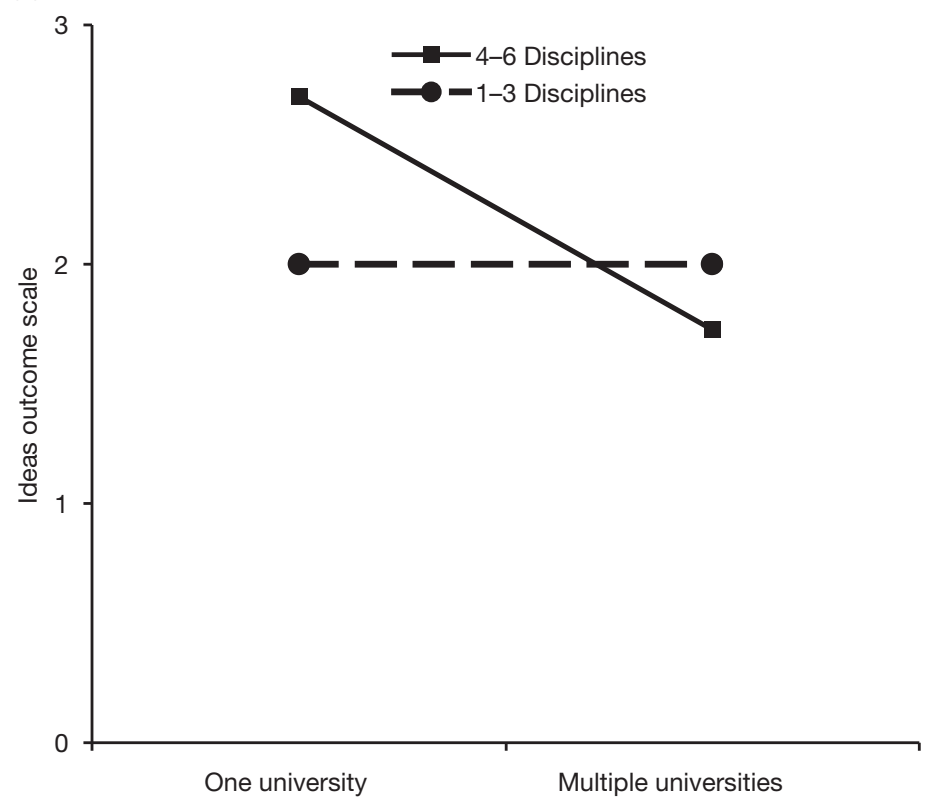

(B)

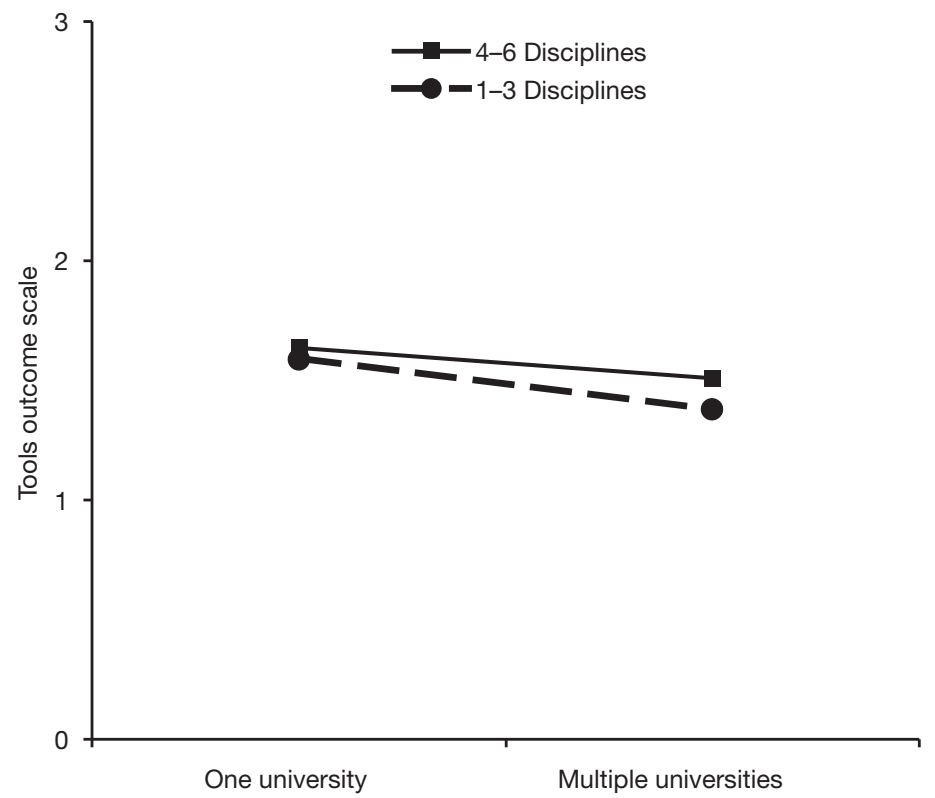




\section{FIGURE 3}

Continued.

(C)
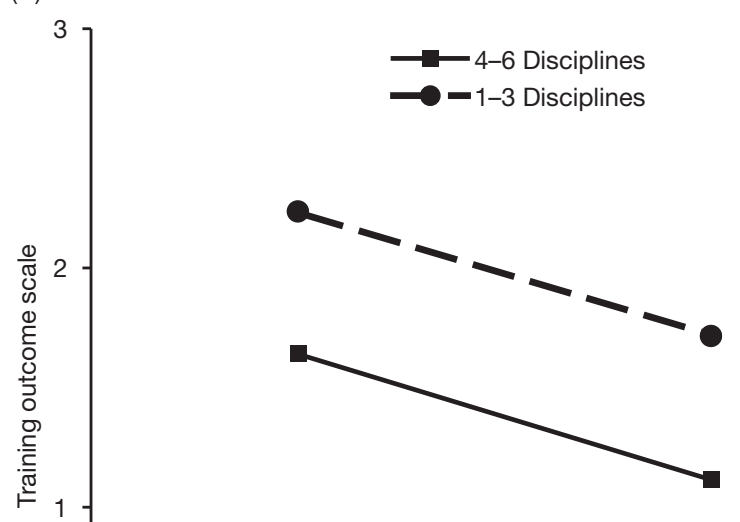

1

(D)

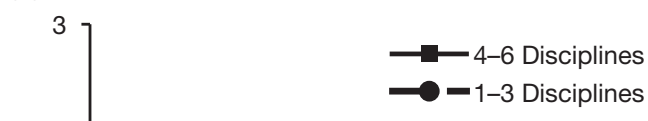

0

One university Multiple universities

$\longrightarrow$-1-3 Disciplines

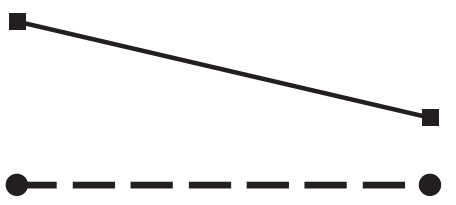


Another problem is that our analysis represents a case study of one funding agency's program and, especially, the beginning of this agency's attempts to support interdisciplinary research on a grander scale. The research program had a number of distinctive attributes that might have influenced the results: for example, that funding was provided for only 3 years, probably insufficient time to create effective coordination for the multi-university projects.

\section{Implications for Theory}

Research on innovation and social networks suggests that multidisciplinary collaborations should generate innovations in science and engineering. Multidisciplinary collaborations can bring new ideas and approaches to a problem. However, the work arrangements that make these collaborations possible require a deliberate strategy for coordination because the natural forces of propinquity and similarity are absent or reduced. In our data, the pattern of coordination in multi-university projects was indeed different than in single university projects.

In managing their projects, the PIs of multi-university projects were less able to supervise all the work directly (and supervision was related strongly to outcomes), to hold regular weekly face-to-face meetings involving the whole group, or to create mechanisms such as co-taught seminars and reading groups that would help the research staff and students share information, learn from one another, and develop professional relationships. They had to travel more and arrange other ways to communicate with participants in the project. Some project leaders jump-started their projects by holding a workshop or conference in which they brought everyone together. Others scheduled monthly telephone meetings. Other groups shared an application, piece of equipment, or database. These mechanisms were sometimes successful, particularly if they were sustained. Monthly phone calls, and regular email and workshops improved outcomes. But investigators complained that funding agencies did not recognize the costs incurred, that budgets did not support the extra coordination efforts needed, and that communication tended to fall off as the dispersed investigators discovered it was easier to work on their own tasks, rather than try to work together. These behaviors suggest that technology did not overcome distance. In multi-university collaborations, leaders and members had to figure out how to keep communication going to create successful projects.

Theories of innovation and social networks have not yet addressed this problem. Social network research mainly focuses on the importance of strong ties for achieving deep exchanges of knowledge and effective learning, and such research is only beginning to address how groups with comparatively weak ties can achieve innovative outcomes (Hansen, 1999). Research on innovation has examined mainly single organization projects in which ties are comparatively strong (Clark \& Wheelwright, 1992). Our study suggests that theories of innovation and social networks could benefit 
from further investigations of how weak ties change into strong ties during the collaboration process. Longitudinal data with measures taken at multiple time periods would be required for such analysis, and cannot be addressed with our cross-sectional data.

Currently, we have no theory of the 'ideal' level of collaboration in science, especially in interdisciplinary science. Our results suggest that student training benefits from less collaboration across disciplines or universities (see Figure 3). The most successful training outcomes were in one university with fewer disciplines involved in the project. In future research, we should examine how different kinds of science use different forms of coordination, and how the use of those mechanisms changes the nature of the collaboration. It may be the case that some mechanisms are more effective than others for tightly coupled, compared with loosely coupled, projects (Weick, 1979). For example, the data in Figure 3 suggest that work on tools and infrastructure (especially software projects) is not impeded at all by multiple disciplines or universities. This is work that can be decomposed, managed, and evaluated across distance and organizational boundaries, as is indicated by the success of many open source projects (for example, Linux, Mozilla).

\section{Implications for Practice}

Our findings should stimulate discussion about the organization and management of funding agencies' multidisciplinary programs and largescale initiatives, and also about approaches that researchers themselves can use to manage multidisciplinary projects. Given the importance of face-toface supervision and coordination, which is apparent in our data, perhaps more project-related conferences, workshops, sabbaticals, and travel to other sites would improve the opportunity for supervision in multiuniversity collaborations. Additional research is needed to identify the incentives that would encourage multi-organizational collaborations to explicitly use coordination mechanisms in their projects.

The use of communication technology (email, instant messages, phone conferences, and video-conferences) did not give PI at multiple universities an added advantage, at least as far as we could determine. Websites were common, though they were rarely used for ongoing work. Our impression from the workshop was that email was used a great deal, but that it failed to help people coordinate project work across many investigators located at different places. Using email sometimes encouraged too much task decomposition and too little intra-project sharing and learning. What kinds of technology might help? Our data, and comments at the workshop, suggest the requirements of such technology would include:

- tools to manage and track the trajectory of tasks over time;

- tools to reduce information overload;

- tools for ongoing conversation (perhaps some version of instant messages for scientists);

- tools for awareness with reasonable interruption for spontaneous talk; 
- tools to support simultaneous group decision-making;

- tools to schedule presentations and meetings across distance.

It is likely that these suggestions apply not only to the comparatively small multi-university collaborations we studied, but also to bigger projects focused on large-scale data analysis and visualization, such as Biomedical Informatics Research Network (BIRN), Network for Earthquake Engineering Simulation (NEES), and Grid Physics Network (GriPhyN).

\section{Implications for Policy}

Policymakers in the research establishment must understand the difficulties of projects that cross distance and organizational boundaries, and decide if they are willing to invest in their extra coordination costs to make them successful. What really accounts for the difficulties associated with such projects? Are they inherently more difficult? Does it simply take more time and effort to get them started? Or do investigators simply have too little skill or time to manage distributed work arrangements? At the KDI workshop, a litany of issues was raised ranging from the difficulty of arranging meetings and joint courses when different universities have different teaching calendars, to the difficulty of meeting expectations of different researchers in different departments. Some university departments, believing that they were on the periphery of the problem, did not reward investigators for their work. Some projects fell apart when their budgets were cut and resources had to be redistributed. (For example, in one project whose budget was cut, one of the co-PIs at a distant university was cut out of the grant entirely.) In some cases, the subcontracting mechanism delayed progress while co-PIs waited for funding. It is not difficult to imagine that the problems become even more severe when national and language boundaries are introduced, as in case of the European Union Framework Programmes.

The experiences expressed at the workshop and analyzed by our survey suggest that funding agencies should consider a number of changes to meet the challenges of multi-organizational collaborations. Changes were made in some programs: for instance, longer-term funding to build infrastructure and relationships and collaborative grant mechanisms instituted in NSF's Information Technology Research program. Further changes that funding agencies should make include, for example, budgets to support an infrastructure for multi-university collaborations and PI salary support. In addition, the practice of encouraging a funding target and then cutting budgets has caused needless stress and resentment by researchers who developed proposals while assuming a particular distribution of resources. The entire community should reconsider the costs of 'proposal pressure'. Researchers, like everyone else, respond to the promise of large-scale funding despite poor chances of funding. More than 1000 researchers wrote full applications for KDI research funding and did not 
receive awards. These proposals were required to be innovative and interdisciplinary, but it seems likely that many involved work that the investigators would have done anyway. If, under a conservative estimate, it took each group only 3 weeks to write its proposal, then the aggregate effort represents 3000 weeks of wasted scientific labor. Because funding agencies do not currently study unfunded proposals and unsuccessful applicants, we cannot answer this question.

\section{Conclusion}

The question of how to promote collaboration across disciplines and organizations applies to innovation systems beyond science. Hence the tradeoff we have characterized here - innovation opportunities versus coordination costs - is a general question. We show that the dilemma is serious. There may be organizational and technological ways to alleviate it.

\section{Notes}

This work was supported by NSF Award no. IIS-9872996. We thank Allyson Pottmeyer and Maria Ines Garcia for their excellent research assistance throughout the project. We also thank Suzanne Iacono for her helpful research suggestions and critiques of findings.

\section{References}

Allen, Thomas (1977) Managing the Flow of Technology (Cambridge, MA: MIT Press). Amabile, Theresa M. (1988) 'A Model of Creativity and Innovation in Organizations', Research in Organizational Behavior 10: 123-67.

Baron, Robert M. \& David A. Kenny (1986) 'The Moderator-Mediator Variable Distinction in Social Psychological Research: Conceptual, Strategic, and Statistical Considerations', fournal of Personality E Social Psychology 51: 1173-82.

Carlsson, Bo, Staffan Jacobsson, Magnus Holmén \& Annika Rickne (2002) 'Innovation Systems: Analytical and Methodological Issues', Research Policy 31: 233-45.

Chin, George, James Myers \& David Hoyt (2002) 'Social Networks in the Virtual Science Laboratory', Communications of the ACM 45(8): 87-92.

Chompalov, Ivan, Joel Genuth \& Wesley Shrum (2002) 'The Organization of Scientific Collaborations', Research Policy 31: 749-67.

Clark, Kim B. \& Steven C. Wheelwright (1992) 'Organizing and Leading "Heavyweight" Development Teams', California Management Review 34(3): 9-28.

Cramton, Catherine Durnell (2001) 'The Mutual Knowledge Problem and its Consequences in Dispersed Collaboration', Organization Science 12(3): 346-71.

Finholt, Thomas A. (2002) 'Collaboratories', Annual Review of Information Science and Technology 36: 73-107.

Finholt, Thomas A. \& Gary M. Olson (1997) 'From Laboratories to Collaboratories: A New Organizational Form for Scientific Collaboration', Psychological Science 8(1): $28-36$.

Granovetter, Mark S. (1973) 'The Strength of Weak Ties', American fournal of Sociology 78: $1360-80$.

Grinter, Rebecca E., James D. Herbsleb \& Dewayne E. Perry (1999) 'The Geography of Coordination: Dealing with Distance in R\&D Work', GROUP (Phoenix, AZ: ACM).

Hagstrom, Warren O. (1964) 'Traditional and Modern Forms of Scientific Teamwork', Administrative Science Quarterly 9(3): 241-64. 
Hansen, Morten T. (1999) 'The Search-Transfer Problem: The Role of Weak Ties in Sharing Knowledge across Organization Subunits', Administrative Science Quarterly 44: $82-111$.

Hargadon, Andrew B. (1998) 'Firms as Knowledge Brokers: Lessons in Pursuing Continuous Innovation', California Management Review 40(3): 209-27.

Henderson, Rebecca M. \& Kim B. Clark (1990) 'Architectural Innovation: The Reconfiguration of Existing Product Technologies and the Failure of Established Firms', Administrative Science Quarterly 35(1): 9-30.

Herbsleb, James D., Audris Mockus, Thomas A. Finholt \& Rebecca E. Grinter (2000) 'Distance, Dependencies, and Delay in a Global Collaboration', Proceedings of the 2000 ACM Conference on Computer Supported Cooperative Work (New York: ACM Press): 319-28.

Hesse, Bradford W., Lee S. Sproull, Sara B. Kiesler \& John P. Walsh (1993) 'Returns to Science: Computer Networks and Scientific Research in Oceanography', Communications of the ACM 36(8): 90-101.

Hinds, Pamela \& Diane Bailey (2003) ' Out of Sight, Out of Sync: Understanding Conflict in Distributed Teams', Organization Science 14(6): 615-32.

Hobday, Mike (2000) 'The Project-Based Organisation: An Ideal Form for Managing Complex Products and Systems?', Research Policy 29: 871-93.

Kiesler, Sara \& Jonathon Cummings (2002) 'What Do We Know about Proximity and Distance in Work Groups?', in P. Hinds \& S. Kiesler (eds), Distributed Work (Cambridge, MA: MIT Press): 57-80.

Kouzes, Richard T., James D. Myers \& William A. Wulf (1996) 'Collaboratories: Doing Science on the Internet', IEEE Computer 29(8): 40-46.

Kraut, Robert E. \& Lynn A. Streeter (1995) 'Coordination in Software Development', Communications of the ACM 38(3): 69-81.

Kraut, Robert E., Carmen Egido \& Jolene Galegher (1990) 'Patterns of Contact and Communication in Scientific Research Collaboration', in J. Galegher, R. Kraut \& C. Egido (eds), Intellectual Teamwork: Social and Technological Bases of Cooperative Work (Hillsdale, NJ: Lawrence Erlbaum): 149-71.

Malone, Thomas W. \& Kevin Crowston (1994) 'The Interdisciplinary Study of Coordination', ACM Computing Surveys 26(1): 87-119.

Mark, Gloria, Jonathan Grudin \& Steven E. Poltrock (1999) 'Meeting at the Desktop: An Empirical Study of Virtually Collocated Teams', European Conference on Computer Supported Cooperative Work, Copenhagen, Denmark (12-16 September).

O'Connor, Gina \& Mark P. Rice (2001) 'Opportunity Recognition and Breakthrough Innovation in Large Established Firms', California Management Review 43(2): 95-116.

Schunn, Christian, Kevin Crowley \& Takeshi Okada (2002) 'What Makes Collaborations Across a Distance Succeed? The Case of the Cognitive Science Community', in P. Hinds \& S. Kiesler (eds), Distributed Work (Cambridge, MA: MIT Press): 407-30.

Sonnenwald, Diane S. (2003) 'The Conceptual Organization: An Emergent Organizational Form for Collaborative R\&D', Science and Public Policy 30(4): 261-72.

Teasley, Stephanie \& Steven Wolinsky (2001) 'Scientific Collaborations at a Distance', Science 292: 2254-55.

Utterback, James M. (1994) Mastering the Dynamics of Innovation (Boston, MA: Harvard Business School Press).

Van de Ven, Andrew H., Andre L. Delbecq \& Richard Koenig Jr (1976) 'Determinants of Coordination Modes within Organizations', American Sociological Review 41: 322-38.

Walsh, John \& Todd Bayma (1996) 'Computer Networks and Scientific Work', Social Studies of Science 26: 661-703.

Weick, Karl E. (1979) The Social Psychology of Organizing (Reading, MA: Addison-Wesley). Zare, Richard N. (1997) 'Knowledge and Distributed Intelligence', Science 275: 1047.

Jonathon N. Cummings is an Associate Professor of Management at the Fuqua School of Business, Duke University. Through the support of an NSF 
Early Career Award (no. IIS-0347705), he studies innovation in geographically dispersed teams and networks.

Address: Fuqua School of Business, Duke University, 1 Towerview Drive (Room A215), Durham, NC 27708, USA; Fax: +1 919681 0244; email: jonathan.cummings@duke.edu

Sara Kiesler is Hillman Professor of Computer Science and Human Computer Interaction at Carnegie Mellon University. She is conducting research on collaboration in multidisciplinary research teams, hospitals, police departments, and geographically dispersed nonprofit organizations.

Address: Human-Computer Interaction Institute, Carnegie Mellon University, 5000 Forbes Ave. (NSH 3513), Pittsburgh, PA 15213, USA; fax: +1 412268 1266; email: kiesler@cs.cmu.edu 